BMJ Open Sport \& Exercise Medicine

\title{
Benefits of a novel concept of home-based exercise with the aim of preventing aspiration pneumonia and falls in frail older women: a pragmatic controlled trial
}

\author{
Katsuhiko Takatori, ${ }^{1}$ Daisuke Matsumoto, ${ }^{1}$ Munenori Nishida, ${ }^{2}$ \\ Shinnichiro Matsushita, ${ }^{3}$ Tatsuya Noda, ${ }^{4}$ Tomoaki Imamura ${ }^{4}$
}

\section{ABSTRACT}

To cite: Takatori $\mathrm{K}$ Matsumoto D, Nishida M, et al. Benefits of a novel concept of home-based exercise with the aim of preventing aspiration pneumonia and falls in frail older women: a pragmatic controlled trial. BMJ Open Sport Exerc Med 2016;2: e000127. doi:10.1136/ bmjsem-2016-000127

- Prepublication history and additional material is available. To view please visit the journal (http://dx.doi.org/ 10.1136/bmjsem-2016000127)

Accepted 23 May 2016

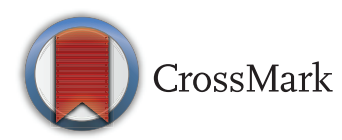

For numbered affiliations see end of article.

Correspondence to Dr Katsuhiko Takatori; k.takatori@kio.ac.jp
Aim: To investigate whether home-based exercise with the aim of preventing aspiration pneumonia and accidental falls improves swallowing-related and physical functions in community-dwelling frail older women.

Methods: Participants were 266 community-dwelling frail older women in a long-term care prevention class (mean (SD): age 75 (5) years). Participants were allocated to either an intervention group or a control group. In the intervention group, participants were asked to perform, at least three times a week for 6 months, a home-based exercise programme that was specifically developed to prevent aspiration pneumonia and accidental falls. Control group participants were instructed to perform general stretching exercises only. Voluntary peak cough flow and lip closure force were measured as swallowing-related functions. Static and dynamic balance function, lower limb strength and flexibility were measured as secondary outcomes. Intervention effects were determined using t tests; effect sizes were calculated using Cohen's d.

Results: Voluntary peak cough flow in the intervention group was significantly greater than in the control group $(p<0.01, d=0.5)$. However, lip closure force did not differ between groups. Regarding physical function, results of the Timed Up and Go Test ( $p<0.05, d=0.4)$, Chair Stand Test $(p<0.01, d=0.4)$, maximal knee extension strength $(p<0.05, d=0.4)$, and Sit and Reach Test $(p<0.05, d=0.3)$ showed greater improvement in the intervention group.

Conclusions: Specifically developed home-based exercise as described in this study is simple and can be performed briefly. Improvements in voluntary peak cough flow and physical function indicate the possible usefulness of such exercise in preventing falls and aspiration pneumonia in community-dwelling frail older adults.

Trial registration number UMIN Clinical Trials Registry (UMIN-CTR): UMIN000014880.

\section{INTRODUCTION}

Japan has the world's leading life expectancy and efforts to extend the healthy life

\section{What are the new findings?}

- For the purpose of preventing aspiration pneumonia and accidental falls, we developed a new concept of home-based exercise that combines training in oral/respiratory function and balance.

- After exercise sessions three times a week or more for a 6-month intervention period, significant improvements were seen in voluntary peak cough flow and dynamic balance functions.

- The home-based exercise programme that we developed for prevention of aspiration pneumonia and falls improved cough and motor functions in community-dwelling frail elders.

expectancy of the elderly are important. ${ }^{1}$ Myocardial infarction, stroke and cancer had been the three major causes of death in Japan for many years. Because of an increase in mortality due to pneumonia and a decrease in mortality due to stroke in recent years, mortality from pneumonia exceeded that of stroke in 2012, to become the third leading cause of death. ${ }^{2}$ Among deaths from pneumonia in the elderly, aspiration pneumonia accounted for about $70 \%$, and it was reported to account for about $90 \%$ of such deaths among those aged 90 years or older. ${ }^{3}$ Because of these facts, efforts to prevent aspiration pneumonia have arisen in a variety of health-related areas (ie, fields of nursing, dentistry, oral care, rehabilitation, etc). In general, the local approach is often used for rehabilitation of dysphagia, such as with ice massage to the perioral area, ${ }^{4}$ movement of the tongue and stretching of the neck. In addition, the Pushing exercise ${ }^{5}$ to strengthen the glottal closure function and 
the Shaker exercise ${ }^{6}$ for strengthening the suprahyoid muscle group as special exercise therapy have been applied. However, even with these approaches, evidence is lacking on prevention of aspiration pneumonia and improvement in the swallowing function. Because the normal swallowing process is basically performed involuntarily by the pharyngeal phase of the swallowing reflex, it is not easy for exercise therapy to improve this reflex. On the other hand, it was shown that the risk of aspiration was increased by insufficient lung capacity and decreased laryngeal elevation due to poor posture. ${ }^{7}$ Furthermore, activity of abdominal muscles is important for the cough function, which is an important defense reaction to prevent aspiration. ${ }^{8}$ Unlike an approach to improve the swallowing reflex itself, it is considered that improvement in these factors can be expected through a therapeutic exercise programme using the whole body.

Whole body movements such as for trunk muscle strengthening and posture improvement can be combined with exercise for lower limb muscle strengthening and improvement in important balance functions for fall prevention. We have developed a new home-based exercise programme (Goen-ni Naran Taiso) for the purpose of preventing falls and aspiration pneumonia, as part of the Nara Prefecture Healthy Long Life Joint Venture.

The purpose of this study is to investigate the impact of implementation, on a regular basis, of 'Goen-niNaran-Taiso' on the balance and swallowing functions of frail community-dwelling elderly women.

\section{METHODS}

\section{Participants}

Participants in this study were 266 community-dwelling elderly women whose condition corresponded to the definition of 'frail elderly' in the 'Kihon checklist', 10 established by the Ministry of Health, Labour and Welfare (table 1). Participants were recruited from seven long-term care prevention classes among seven towns and cities in the Nara prefecture in Japan from the 1 to 30th of September, 2014. The participants were excluded if they met any of the following exclusion criteria: (A) the presence of a chronic exhausting disease such as malignancy or infection, (B) involvement in another home exercise programme, $(\mathrm{C})$ regular participation in an exercise class, (D) they could not perform the exercise programme due to severe joint pain and (E) being diagnosed with dementia.

\section{Design and intervention}

The present study was a single-blinded, pragmatic controlled clinical trial with participants allocated to an intervention group $(n=148)$ or control group $(n=118)$, according to the choice of the participant. Since the recruitment of participants was performed as part of a community support project by the government, we had an ethical obligation to provide the intervention programme to any participant who preferred to receive the intervention. Therefore, it was not possible to randomise the participants. The intervention group first received guidance from research physical therapists in the home-

Table 1 Participants' baseline characteristics

\begin{tabular}{|c|c|c|c|}
\hline Variables & Control group $(n=118)$ & Intervention group $(n=148)$ & p Value \\
\hline Age (years) & $75.9(6.0)$ & $74.6(5.1)$ & 0.074 \\
\hline $5 \mathrm{~m}$ walking time (s) & $3.22(1.32)$ & $3.08(1.43)$ & 0.427 \\
\hline TUG-T (s) ${ }^{*}$ & $7.28(1.64)$ & $7.04(2.76)$ & 0.411 \\
\hline FRT (cm)† & $30.4(7.6)$ & $30.5(7.9)$ & 0.946 \\
\hline CS-30 (times) $\ddagger$ & $17.1(5.9)$ & $17.8(5.7)$ & 0.366 \\
\hline Sway path EO§ $(\mathrm{cm} / \mathrm{s})$ & $1.58(0.7)$ & $1.58(0.8)$ & 0.671 \\
\hline Sway path ECI (cm/s) & $2.3(1.3)$ & $2.4(1.2)$ & 0.811 \\
\hline Knee extension strength (\% body weight) & $36.2(14.2)$ & $38.2(13.6)$ & 0.397 \\
\hline Sit and Reach Test $(\mathrm{cm})$ & $14.2(8.6)$ & $14.7(9.3)$ & 0.534 \\
\hline VPCF $(\ell / \min )^{\star *}$ & $252.0(100.3)$ & $272.9(123.1)$ & 0.160 \\
\hline LCF $(\mathrm{kg}) \dagger \dagger$ & $8.7(3.7)$ & $9.5(3.8)$ & 0.161 \\
\hline LSNS-6 $\ddagger$ & $16.8(5.3)$ & $17.4(6.3)$ & 0.548 \\
\hline M-FES§§ & $135.9(8.1)$ & $135.6(5.1)$ & 0.744 \\
\hline Number of fallers (persons)ๆা & $38(32 \%)$ & $38(26 \%)$ & 0.242 \\
\hline \multicolumn{4}{|c|}{ 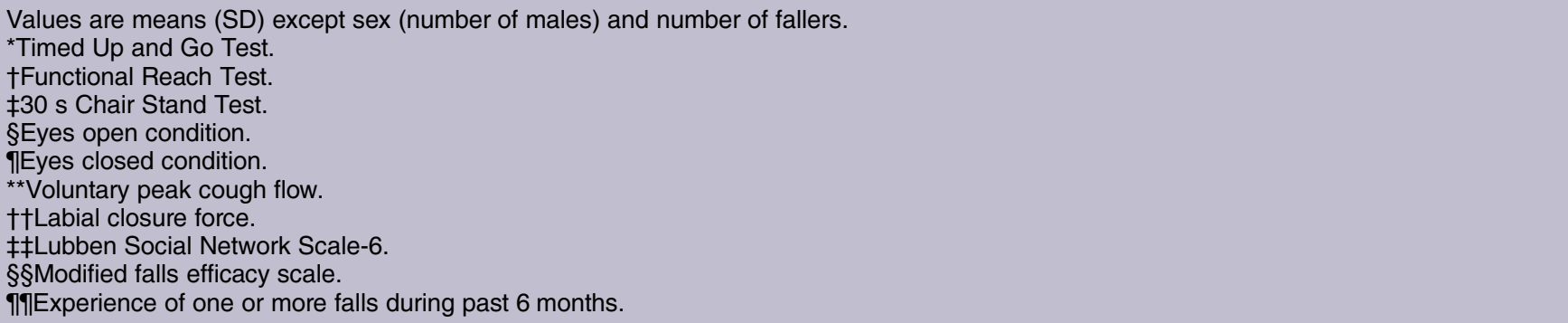 } \\
\hline
\end{tabular}


based exercise programme that we developed. Then, the brochures and original DVD that we created showing the exercise programme were distributed to all participants for practice (see online supplementary video file). We instructed the participants to perform the exercise programme at home at least three times a week and to record each session on a calendar.

The home-based exercise programme had 12 elements that combined stretching, breathing exercises, balance training, muscle strengthening and dual-task training (ie, simultaneous processing of cognitive tasks and motor tasks) (table 2). The time required per session was about 5 min. Horizontal movement (ie, protraction) of the head was aimed to expand the mesopharynx space (Item number 3); strong exhalation and body axis rotation in a single-leg standing position aimed to strengthen the oblique abdominal muscle and peak cough force (Item number 7); and the combination of a forward lunge for lower limb muscle strengthening and the Pushing exercise ${ }^{5}$ for improvement of the glottal closure function (Item number 8)-are the distinctive movements in this programme. Participants in the control group were advised to maintain or improve their activity in daily life and attend lectures on health. All participants gave informed consent for participation in the study. This study was reviewed and approved by the ethical committee of the Kio University (number H24-20). This study was registered to UMIN-CTR (UMIN000014880) on 1 September 2014.

Sample size estimation was based on results of our preliminary study measuring voluntary peak cough flow (VPCF) in older community-dwelling adults $(\mathrm{N}=34$, $\mathrm{d}=0.6$ ). A sample size of at least 45 persons per group was needed to detect significant differences between groups with a level of $\alpha=0.05$, a desired power of $80 \%$ and a Cohen's $\mathrm{d}=0.6$. To accommodate a possible $10 \%$ dropout rate before study completion, we established a total of 50 or more participants per group to be required for this study.

At the baseline and after 6 months, all participants were assessed for outcome variables by assessors blinded to the allocation of the participants. The VPCF and maximum labial closure force (LCF) were used as primary outcome variables, as they have a reliable relationship with the strength of cough and swallowing function. ${ }^{11}{ }^{12}$ VPCF, defined as the maximal flow volume with a voluntary cough, was assessed using a spirometer (Harada Co, Ltd, Osaka, Japan). Participants were instructed to wear an expired-gas analysis mask and cough as strongly as possible after maximum air intake while in the sitting position. Measurements were taken twice, and the average value of VPCF was recorded. LCF was measured using a Lip-de-Cum and Duckling (Cosmo Instruments Co, Ltd, Tokyo, Japan). LCF was measured by the following procedure in accordance with a previous study: ${ }^{13}$ Participants in a sitting position were fitted with a device (Duckling), covering large areas of the upper and lower lips, through which the sensor in the LCF measuring instrument (Lip-de-Cum) was inserted. They were then instructed not to bite with the upper and lower jaw but to close the upper and lower lips with maximum force for $15 \mathrm{~s}{ }^{14}$

Static and dynamic balance ability, lower limb strength and body flexibility were assessed as secondary

Table 2 Contents of the home-based exercise programme

\begin{tabular}{|c|c|c|c|}
\hline Item & Category & Motion & Aim \\
\hline 1 & Neck stretching & Flexion-extension & Improve neck flexibility \\
\hline 2 & & Side bending & \\
\hline 3 & & Protraction/retraction of head & $\begin{array}{l}\text { Expand the mesopharynx } \\
\text { space }\end{array}$ \\
\hline 4 & Trunk and thorax stretching & Side bending and extension & Improve thorax flexibility \\
\hline 5 & Balance training & $\begin{array}{l}\text { Turn the hips in a circular motion (shift of the centre } \\
\text { of gravity) }\end{array}$ & \\
\hline 6 & $\begin{array}{l}\text { Combination of balance and } \\
\text { breath training }\end{array}$ & $\begin{array}{l}\text { Multidirectional step with breath holding (firmly } \\
\text { closing lips) }\end{array}$ & Strengthen lip closure force \\
\hline 7 & $\begin{array}{l}\text { Combination of trunk muscle } \\
\text { strengthening and breath } \\
\text { training }\end{array}$ & $\begin{array}{l}\text { In standing or sitting position, one side of the elbow } \\
\text { and the other side of the knee moved closer while } \\
\text { twisting the trunk, with powerful exhalation }\end{array}$ & Strengthen lip closure force \\
\hline 8 & Pushing exercise & $\begin{array}{l}\text { Breath holding-powerful exhalation with arm } \\
\text { pushing }\end{array}$ & $\begin{array}{l}\text { Improve breathing and pattern } \\
\text { of swallowing and exhalation } \\
\text { power }\end{array}$ \\
\hline 9 & $\begin{array}{l}\text { Combination of lower limb } \\
\text { strengthening and breath } \\
\text { training }\end{array}$ & $\begin{array}{l}\text { Simultaneous execution of the above and forward } \\
\text { lunge exercise }\end{array}$ & $\begin{array}{l}\text { Strengthen lower limb strength } \\
\text { in addition to the above }\end{array}$ \\
\hline 10 & Dual-task training & Box step and clap hands & $\begin{array}{l}\text { Improve body balance and } \\
\text { cognitive function }\end{array}$ \\
\hline 11 & Tai-chi motion & Slow side step with exhalation & Improve body balance ability \\
\hline 12 & Deep breath & Deep breathing with arm elevation & Expansion of thorax \\
\hline
\end{tabular}


outcomes. To measure static balance ability, we measured the centre of gravity's sway path length per second, using a stabilometer (Gravicorder GP-31, Anima Co, Ltd, Tokyo, Japan) under conditions of open eyes and closed eyes. The $5 \mathrm{~m}$ walking time (maximal speed), Timed Up and Go Test (TUG-T) ${ }^{15}$ and Functional Reach Test $(\text { FRT })^{16}$ were assessed as indicators of dynamic balance. We measured maximal knee extension strength, using a hand-held dynamometer ( $\mu$ Tas F-1, Anima Co, Ltd) and used the 30-s Chair Stand Test (CS-30) to evaluate lower limb muscle strength and power. ${ }^{17}$ To measure maximum knee extension strength, we recorded the maximum isometric muscle strength of the knee at $90^{\circ}$ flexion with the participant seated in a chair without using the backrest. Measurements were performed twice after one practice session, and the maximum value was recorded. Flexibility of the body was evaluated using the Sit and Reach Test. ${ }^{18}$ Using a questionnaire, we examined the amount of each participant's social support (using the Lubben Social Network Scale- $6^{19}$ ), history of falls in the past 6 months (number of falls) and fear of falling (using the Modified Falls Efficacy Scale). ${ }^{20}$

\section{Data analysis}

Statistical analysis was performed using JMP statistical software, V.9.0.0 (SAS Institute Inc, Tokyo, Japan). $\mathrm{p}$ Values less than 0.05 indicated statistical significance. Student's t tests and $\chi^{2}$ tests were used to examine the differences in baseline demographic features and physical function between groups. Pre-post within-group differences in variables were compared using paired $t$ tests. The main analysis of all outcomes examined whether differences at 6 months postintervention existed between the intervention and control groups. To examine the effects of the intervention, a Student's t test was used to compare the amount of change between groups. The inter-group effect size was calculated according to Cohen's d statistic. ${ }^{21}$ An effect size $<0.2$ reflected a negligible difference, between $\geq 0.2$ and $\leq 0.5$ a small difference, between $>0.5$ and $\leq 0.8$ a moderate difference, and $>0.8$ a large difference.

\section{RESULTS}

At the baseline measurements, there were no significant differences in demographic features and physical functions between the intervention group and control group. Among the 148 participants in the intervention group, 138 participants $(93.2 \%)$ completed the programme three times a week (median: 3 times, IQR, 3-3). No adverse events were reported for any participant after the intervention. In the intervention group, 10 participants stopped performing the exercise (lost interest in exercise: 8 participants, reason not known: 2 participants) and two people did not participate in the outcome measurement after the intervention. Of the 118 participants enrolled in the control group, 72 $(61.0 \%)$ completed all assessments and 46 participants did not undergo outcome measurements (personal reason: 14 participants, health problem: 3 participants, reason not known: 29 participants). No significant differences in sociodemographic and physical features were found between intervention group and control group participants who did not participate in the final evaluation or who dropped out (table 3).

A within-group comparison of each variable after the 6-month study period showed significant improvement in VPCF, 5 m-walking time, Sway path (eyes closed condition), TUG-T, FRT, Sit and Reach Test, maximal knee extension strength and CS-30 in the intervention group. On the other hand, no significant improvements were found in any of the variables in the control group. To demonstrate the effect of our programme, results of between group comparisons showed greater improvement in the VPCF $(p=0.004, d=0.47)$, TUG-T $(p=0.02$, $\mathrm{d}=0.38)$, Sit and Reach Test $(\mathrm{p}=0.03, \mathrm{~d}=0.33)$, knee extension strength $(\mathrm{p}=0.03, \quad \mathrm{~d}=0.35)$ and CS-30 $(p=0.007, d=0.42)$ in the intervention group (table 4$)$. Furthermore, results of the $\chi^{2}$ test showed that the incidence of falls during the study period was reduced significantly in the intervention group (38 participants $(26 \%)$ at baseline, 17 participants $(12 \%)$ at the end of study period, $\left.\chi^{2}=8.20, p<0.01\right)$. In the control group, there was no significant reduction in the incidence of falls including that in dropouts (38 participants (32\%) at baseline, 26 participants (22\%) at the end of study period, $\left.\chi^{2}=3.09, \mathrm{p}=0.07\right)$. Between group comparisons showed that there was a significant reduction in fall incidence in the intervention group $\left(\chi^{2}=5.38, \mathrm{p}<0.05\right)$.

\section{DISCUSSION}

In Japan, because of the extension of a healthy life expectancy, a number of home-based exercise programmes have been developed. ${ }^{22-24}$ Many of these are focused only on the improvement of motor function, such as lower extremity muscle strength or whole body balance. On the other hand, oral exercises aimed at improvement in swallowing function, such as oral diadochokinesis, ${ }^{25}$ do not contain elements of a whole-body exercise programme that combines oral movement and whole body motion. In addition, since the effects of general oral exercises have not been demonstrated using objective measures, their effectiveness has not been clarified. The home-based exercise programme used in this study is comprised of general oral exercise and neck and thorax stretching, breathing exercise, balance exercise and whole body movements such as those to strengthen the lower extremities and trunk muscles.

Results showed significant improvement in VPCF in the intervention group. We believe that the reason for this result is the combined effect of trunk rotation movement with the aim of strengthening many breath movements (Pushing exercise and Tai-chi component) and the abdominal oblique muscle in this programme. A previous study indicated the necessity of at least 240e/ 
Table 3 Between group comparison of physical performance parameters between participants who did not complete trial or who dropped out

\begin{tabular}{|c|c|c|c|}
\hline Variables & Control group $(n=46)$ & Intervention group $(n=10)$ & p Value \\
\hline Age (years) & $76.2(6.8)$ & $73.7(4.3)$ & 0.271 \\
\hline $5 \mathrm{~m}$ walking time (s) & $2.88(0.83)$ & $2.67(0.38)$ & 0.442 \\
\hline TUG-T $(s)^{*}$ & $6.94(1.84)$ & $6.13(1.26)$ & 0.187 \\
\hline $\mathrm{FRT}(\mathrm{cm}) \dagger$ & $29.1(7.4)$ & $29.0(8.5)$ & 0.982 \\
\hline CS-30 (times) $\ddagger$ & $19.5(7.7)$ & $19.1(7.0)$ & 0.865 \\
\hline Sway path EO§ $(\mathrm{cm} / \mathrm{s})$ & $1.36(0.61)$ & $1.39(0.36)$ & 0.897 \\
\hline Sway path ECף $(\mathrm{cm} / \mathrm{s})$ & $1.85(0.76)$ & $2.26(0.91)$ & 0.139 \\
\hline Knee extension strength (\%BW) & $40.1(12.7)$ & $41.4(12.2)$ & 0.761 \\
\hline Sit and Reach Test $(\mathrm{cm})$ & $19.5(7.7)$ & $19.1(7.0)$ & 0.866 \\
\hline $\operatorname{VPCF}(\ell / \mathrm{min})^{\star *}$ & $263.0(123.8)$ & $225.5(77.1)$ & 0.255 \\
\hline LCF $(\mathrm{kg}) \dagger \dagger$ & $8.5(2.9)$ & $8.6(4.6)$ & 0.932 \\
\hline LSNS-6‡‡ & $18.5(4.2)$ & $18.7(6.2)$ & 0.919 \\
\hline M-FES§§ & $36.7(4.1)$ & $37.0(3.2)$ & 0.849 \\
\hline Number of fallers & $3(6 \%)$ & $0(0 \%)$ & 0.406 \\
\hline \multicolumn{4}{|c|}{ 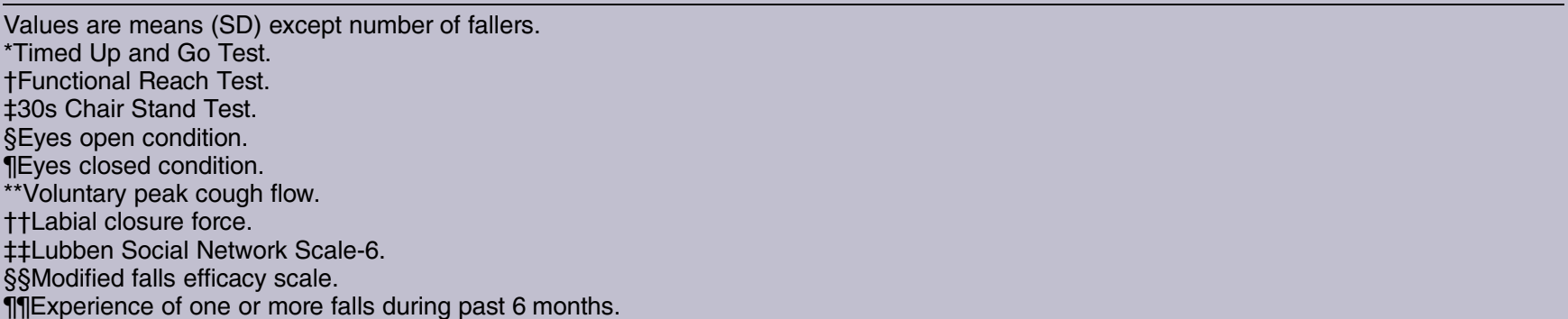 } \\
\hline
\end{tabular}

min or more voluntary cough force for sufficient expectoration. ${ }^{13}$ Among the 39 participants who had VPCF values below the reference value at baseline, 11 participants had VPCF values above the reference value after the intervention. This indicated the possible therapeutic value of exercise in reducing pneumonia risk. There was no significant change before and after the intervention in the LCF, which reflects the swallowing function. The reason might have been that none of the study participants had a lower value than the reference LCF at baseline so an effect of the intervention was not shown explicitly. Improvements in walking speed, TUG-T, knee extension strength and CS-30, reflect the dynamic balance function and improvements in lower limb muscle strength. Therefore, the programme was effective in improving whole body motor function. The dynamic balance function plays an important role in fall prevention and its improvement possibly contributed to the reduction in the incidence of falls in the intervention group.

In the intervention period of 6 months, adherence to the exercise programme was high: $93.2 \%$ of participants performed the exercise at least twice a week. The reason for this could be supported by the fact that participants in the intervention group were provided with the original exercise DVD and a leaflet describing the exercise programme, free of charge, and they could easily perform the exercise at home and without supervision. In addition, each exercise item in the DVD was accompanied by music to match the respective motion. Also, so that the participant could perform only parts of the programme at a given time, the leaflet was divided into chapters. We believe that these support materials affected adherence to the programme.

\section{Limitations}

This study had several limitations. First, this study design was not a randomised controlled trial. The introduction of the home-based exercise programme in this study was not designed for a clinical study, since it was proposed to municipalities as a support programme for community-dwelling elderly people, which may result in a selection bias. In addition, since the participants in the present study were women who were independent in the activities of daily living, generalisation of the study results to apply to elderly men is limited. Second, although VPCF and LCF were principal outcomes of this study, they were surrogate end points that indirectly indicated the swallowing and cough function. In order to directly investigate changes in the swallowing function, it would be necessary to consider the introduction of video endoscopic examinations of swallowing and a simple repetitive saliva swallowing test. ${ }^{26}$ To reach the final goal of this research for a reduction in the incidence of aspiration pneumonia, there is a need for a long-term survey of the participants in this study.

\section{CONCLUSION}

In this study, comparisons in physical functioning were made between a control group that underwent no specific exercise programme and an intervention group that was asked to undertake a $5 \mathrm{~min}$ home-based exercise regimen three times weekly for 6 months. Participants 
Table 4 Within and between group comparison of variables

\begin{tabular}{|c|c|c|c|c|}
\hline Group & $\begin{array}{l}\text { Control group } \\
(n=72)\end{array}$ & $\begin{array}{l}\text { Intervention group } \\
(n=138)\end{array}$ & $\begin{array}{l}\text { Between group } \\
\text { differences }(P)\end{array}$ & Effect size \\
\hline 5 m walking time(s) & $3.00(0.75)$ & $2.96(0.87)$ & 0.06 & \\
\hline Pre & $2.83(0.86)$ & $2.78(0.74)$ & & \\
\hline \multicolumn{5}{|l|}{ Post } \\
\hline Change & $0.16(0.66)$ & $0.18(0.36)$ & 0.716 & \\
\hline \multicolumn{5}{|l|}{ TUG-T(s)† } \\
\hline Pre & $6.55(1.55)$ & $6.83(2.14)$ & & 0.38 \\
\hline Post & $6.70(1.65)$ & $6.60(1.73)^{\star \star}$ & & \\
\hline Change & $-0.15(1.21)$ & $0.24(1.07)$ & 0.022 & \\
\hline \multicolumn{5}{|l|}{ FRT $(\mathrm{cm}) \ddagger$} \\
\hline Pre & $32.3(7.8)$ & $31.3(7.6)$ & & 0.16 \\
\hline Post & $31.0(9.1)$ & $32.7(6.8)^{\star \star}$ & & \\
\hline Change & $-1.2(7.1)$ & $1.4(6.0)$ & 0.291 & \\
\hline \multicolumn{5}{|l|}{ CS-30 (times)§ } \\
\hline Pre & $18.3(6.5)$ & $17.6(5.3)$ & & 0.42 \\
\hline Post & $18.6(6.3)$ & $19.6(5.6)^{\star \star}$ & & \\
\hline Change & $0.3(4.3)$ & $2.0(3.8)$ & 0.007 & \\
\hline \multicolumn{5}{|c|}{ Sway path EO $(\mathrm{cm} / \mathrm{s}) \emptyset$} \\
\hline Pre & $1.52(0.50)$ & $1.50(0.74)$ & & 0.34 \\
\hline Post & $1.46(0.66)$ & $1.65(0.93)$ & & \\
\hline Change & $0.05(0.47)$ & $-0.15(0.70)$ & 0.052 & \\
\hline \multicolumn{5}{|c|}{ Sway path EC $(\mathrm{cm} / \mathrm{s})^{\star \star}$} \\
\hline Pre & $2.24(1.10)$ & $2.37(1.32)$ & & 0.23 \\
\hline Post & $2.22(1.21)$ & $2.17(1.13)^{\star *}$ & & \\
\hline Change & $0.01(0.60)$ & $0.20(0.88)$ & 0.175 & \\
\hline \multicolumn{5}{|c|}{ Knee extension strength (\%BW) } \\
\hline Pre & $35.9(15.0)$ & $38.6(12.5)$ & & 0.35 \\
\hline Post & $36.2(14.4)$ & $41.2(10.5)^{\star \star}$ & & \\
\hline Change & $0.2(8.8)$ & $2.61(9.9)$ & 0.035 & \\
\hline \multicolumn{5}{|c|}{ Sit and Reach Test $(\mathrm{cm})$} \\
\hline Pre & $13.9(8.6)$ & $14.9(9.4)$ & & 0.33 \\
\hline Post & $14.5(10.0)$ & $17.7(9.7)^{\star \star}$ & & \\
\hline Change & $0.6(5.8)$ & $2.8(6.8)$ & 0.046 & \\
\hline \multicolumn{5}{|l|}{ VPCF $(\ell / \min ) \dagger \dagger$} \\
\hline Pre & $242.0(96.3)$ & $273.8(127.4)$ & & 0.47 \\
\hline Post & $249.4(98.1)$ & $316.4(136.5)^{\star \star}$ & & \\
\hline Change & $7.4(73.7)$ & $42.7(95.4)$ & 0.004 & \\
\hline \multicolumn{5}{|l|}{ LCF $(\mathrm{kg}) \ddagger \ddagger$} \\
\hline Pre & $9.22(3.53)$ & $9.77(3.86)$ & & 0.19 \\
\hline Post & $9.30(3.12)$ & 9.67 (4.34) & & \\
\hline Change & $0.07(3.11)$ & -0.09 (4.09) & 0.424 & \\
\hline \multicolumn{5}{|l|}{ Number of fallers§§ } \\
\hline Pre & 38 (32\%) & $38(26 \%)$ & & NA \\
\hline Post & $26(22 \%)$ & $17(12 \%)$ & & \\
\hline Change & $12(10 \%)$ & $21(14 \%)$ & 0.02 & \\
\hline
\end{tabular}

Values are means (SD) except number of fallers. ${ }^{*} p<0.05,{ }^{\star *} p<0.01$ : Pre-Post comparison.

†Timed Up and Go Test.

fFunctional Reach Test.

$\S 30$ s Chair Stand Test.

ПEyes open condition.

**Eyes closed condition.

††Voluntary peak cough flow.

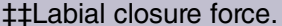

$\S \S$ Experience of one or more falls during past 6 months.

NA, not applicable.

were community-dwelling frail older women. We developed this programme to prevent falls and aspiration pneumonia. Results showed that cough force, balance function and lower limb muscle strength were improved in the intervention group, indicating the efficacy of this simple regimen for preventing falls and aspiration pneumonia. That it can be performed rapidly and at home is an advantage to this ageing population. 
Author affiliations

${ }^{1}$ Department of Physical Therapy, Faculty of Health Sciences, Kio University, Nara, Japan

${ }^{2}$ Department of Rehabilitation, Akitsu-Kounoike Hospital, Nara, Japan

${ }^{3}$ Department of Rehabilitation, Nara Prefecture General Rehabilitation Center, Nara, Japan

${ }^{4}$ Nara Medical University Department of Public Heath, Health Management and Policy, Kashihara, Japan

Acknowledgements The authors gratefully acknowledge Ichiro Takeda, Tatsuya Noda and Misuzu Matsuzaki, for promoting the study and for their help with participant recruitment.

Contributors KT conceived of the study. DM and MN initiated the study design and SM, TN and TI helped with implementation. All the authors contributed to refinement of the study protocol and approved the final manuscript.

Competing interests None declared.

Patient consent Obtained.

Ethics approval The ethical committee of the Kio University (number H24-20).

Provenance and peer review Not commissioned; externally peer reviewed.

Open Access This is an Open Access article distributed in accordance with the Creative Commons Attribution Non Commercial (CC BY-NC 4.0) license, which permits others to distribute, remix, adapt, build upon this work noncommercially, and license their derivative works on different terms, provided the original work is properly cited and the use is non-commercial. See: http:// creativecommons.org/licenses/by-nc/4.0/

\section{REFERENCES}

1. World Health Organization. World health statistics 2014. http://www. who.int/gho/publications/world_health_statistics/2014/en/. accessed 10 Nov 2015).

2. Trends in leading causes of death: Ministry of Health, Labour and Welfare. Annual Health, Labour and Welfare. 2014:15-23.

3. Teramoto S. Current Definition of Aspiration Pneumonia: An Overview. Jpn J Chest Dis 2009;68:795-808.

4. Nakamura T, Fujishima I. Usefulness of ice massage in triggering the swallow reflex. J Stroke Cerebrovasc Dis 2013;22:378-82.

5. Boone RB, McFarlane CS. The voice and voice therapy. 4th edn. Englewood Cliffs, NJ: Prentice Hall, 2000:185-7.

6. Shaker R, Easterling C, Kern M, et al. Rehabilitation of swallowing by exercise in tube-fed patients with pharyngeal dysphagia secondary to abnormal UES opening. Gastroenterology 2002;122:1314-21.

7. Yamashina Y, Tabira K, Masuda T, et al. Influence of posture on cough peak flow, electromyographic activity of the abdominal muscles during coughing. Bull Aino Univ 2011;25:1-6.
8. Abe T, Kusuhara N, Yoshimura N, et al. Differential respiratory activity of four abdominal muscles in humans. J Appl Physiol 1996;80:1379-89.

9. Japanese Ministry of Health, Labour and Welfare. The Manuals of the Evaluation for Ability to Perform Daily Activities on Preventive Care. Japan Ministry of Health, Labour and Welfare. http://www.mhlw.go.jp/ topics/2009/05/dl/tp0501-1c 0001.pdf (accessed 25 Dec 2015).

10. Fukutomi E, Okumiya K, Wada T, et al. Importance of cognitive assessments as part of the "Kihon Checklist" developed by the Japanese Ministry of Health, Labour and Welfare for prediction of frailty at a 2-year follow up. Geriatr Gerontol Int 2013;13:654-62.

11. Reddy NP, Costarella BR, Grotz RC, et al. Biomechanical measurement to characterize the oral phase of dysphagia. IEEE Trans Biomed Eng 1990;37:392-7.

12. Miura $H$, Kariyasu $M$, Sumi $Y$, et al. Labial closure force, activities of daily living, and cognitive function in frail elderly persons. Nihon Ronen Igakkai Zasshi 2008;45:520-5.

13. Yamakawa R, Yokoyama $H$, Watanabe $Y$, et al. The level of cough peak flow for judging ability of clear airway secretion in middle-old age subjects. Japanese J Respir Care 2010;27:260-6.

14. Hayashi R, Tsuga K, Hosokawa R, et al. A novel handy probe for tongue pressure measurement. Int J Prosthodont 2002;15:385-8.

15. Podsiadlo D, Richardson S. The timed "Up \& Go": a test of basic functional mobility for frail elderly persons. J Am Geriatr Soc 1991;39:142-8.

16. Duncan PW, Weiner DK, Chandler J, et al. Functional reach: a new clinical measure of balance. J Gerontol 1990;45:M192-7.

17. Jones CJ, Rikli RE, Beam WC. A 30-s chair-stand test as a measure of lower body strength in community-residing older adults. Res $Q$ Exerc Sport 1999;70:113-19.

18. Roberta E, Rikli C. Jessie Jones: Senior fitness test manual. 2nd edn(Enhanced edition). Human Kinetics Pub, 2012:54-83.

19. Lubben J, Blozik E, Gillmann G, et al. Performance of an abbreviated version of the Lubben social network Scale among three European community-dwelling older adult populations. Gerontologist 2006;46:503-13.

20. Hill KD, Schwarz JA, Kalogeropoulos AJ, et al. Fear of falling revisited. Arch Phys Med Rehabil 1996;77:1025-9.

21. Cohen J. Statistical power analysis for the behavioral sciences. 2nd edn. Hillsdale, NJ: Lawrence Erlbaum, 1988.

22. Shigematsu R, Okura T. A novel exercise for improving lower-extremity functional fitness in the elderly. Aging Clin Exp Res 2006;18:242-8.

23. Yamada M, Tanaka B, Nagai $\mathrm{K}$, et al. Trail walking Trail-walking exercise and fall risk factors in community-dwelling older adults: preliminary results of a randomized controlled trial. J Am Geriatr Soc 2010;58:1946-51.

24. Doi $\mathrm{T}$, Shimada $\mathrm{H}$, Makizako $\mathrm{H}$, et al. Cognitive function and gait speed under normal and dual-task walking among older adults with mild cognitive impairment. BMC Neurol 2014;14:67.

25. Ziegler W. Task-related factors in oral motor control: speech and ora diadochokinesis in dysarthria and apraxia of speech. Brain Lang 2002;80:556-75.

26. Horiguchi S, Suzuki Y. Screening Tests in Evaluating Swallowing Function. JMAJ 2011;54:31-4. Supplementary File-Video: https:// youtu.be/_OrEvauM2xY (accessed 29 January 2016). 